\title{
Palladium-catalyzed coupling of 2-en-4-yne carbonates with terminal alkynes
}

\author{
Doğan Taç, Levent Artok* \\ Department of Chemistry, Faculty of Science, Izmir Institute of Technology, Urla 35431, Izmir, Turkey
}

\section{A R T I C L E I N F O}

\section{Article history:}

Received 30 November 2017

Revised 19 January 2018

Accepted 20 January 2018

Available online 31 January 2018

\begin{abstract}
A B S T R A C T
The first palladium-catalysed coupling of the carbonates of (E)-configured conjugated enynols with terminal alkynes is described. This method allows the synthesis of vinyl-allenynes with good yields. It has been determined that the method is not suitable for the $(Z)$-configured substrates.
\end{abstract}

(c) 2018 Published by Elsevier Ltd.

Keywords:

Alkynylation

Enyne

Allene

Vinylallene

Allenyne

Vinyl-allenyne

\section{Introduction}

It has been established in our laboratory that ester-, aryl-, or alkyl-substituted vinylallenes can be synthesised via transition metal-catalysed reactions of conjugated enynes bearing a leaving group at the allylic position. ${ }^{1}$ Vinylallenes are versatile reagents that can be used at various cycloaddition, cyclisation, and isomerisation reactions. ${ }^{2}$ In particular, their unique reactivity and selectivity in [4+2] reactions have been utilised in the synthesis of several naturally occurring reagents. ${ }^{3}$

Palladium-catalysed processes of these conjugated enyne systems should proceed through the formation of $\sigma$-allenylpalladium intermediates as it is in the analogous reactions of the propargyl compounds (Fig. 1). ${ }^{4}$ Another prominent application that makes use of this organopalladium species is the alkynylation of propargylic reagents, which is widely used for the synthesis of alkynylated allenic products, ${ }^{5}$ which are motifs present in several biologically occurring compounds. ${ }^{6}$ Therefore we decided to extend the methodology to investigate for its suitability in the coupling of the carbonates of 2-en-4-yne alcohols with terminal alkynes to produce vinyl-allenynes. These structurally interesting conjugated and highly unsaturated hydrocarbons are usually not so widely known and studied.

\footnotetext{
* Corresponding author.

E-mail address: leventartok@iyte.edu.tr (L. Artok).
}

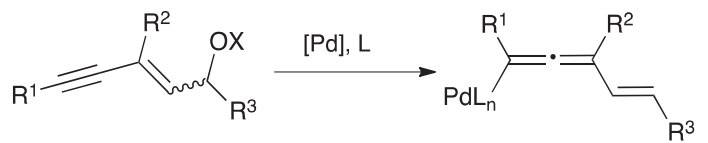

Fig. 1. The formation of $\sigma$-allenylpalladium species from conjugated enynes.

\section{Results and discussion}

After extensive investigations of reaction parameters we found that the use of enyne carbonate $1 \mathbf{a}(0.2 \mathrm{mmol})$ as the model substrate with but-3-yn-1-ol (0.3 mmol, 1.5 equiv), $\mathrm{Pd}_{2}(\mathrm{dba})_{3}-\mathrm{CHCl}_{3}$ (2 mol\% $\mathrm{Pd}$ ), $\mathrm{PPh}_{3}$ (8 mol\%), $\mathrm{KBr}$ (2 equiv), and $\mathrm{Et}_{2} \mathrm{NH}$ (40 equiv) in THF at $55{ }^{\circ} \mathrm{C}$ provided the intended product vinyl-allenyne 2aa in $91 \%$ yield when the reaction was allowed to proceed until the conversion ceased as judged by TLC and appearance of palladium black. (Table 1, entry 1 ). Secondary amine bases appeared to work better as compared to tertiary amines (entries 2-5) and the reduction of the amount of added $\mathrm{Et}_{2} \mathrm{NH}$ by half resulted in a slight decrease in the yield (entry 2). The presence of $\mathrm{KBr}$ additive was found to be beneficial for the product selectivity (entry 6); however, other salt additives used, such as $\mathrm{KI}$ or $\mathrm{LiBr}$ were observed to be quite detrimental for the process efficiency (entries 7 and 8 ). It was apparent that the reaction should be performed under water-free conditions (entry 9). The reaction temperature of 25 ${ }^{\circ} \mathrm{C}$ was not sufficient for the effective conversion of $\mathbf{1 a}$ (entry 10). 
Table 1

The effect of reaction parameters.

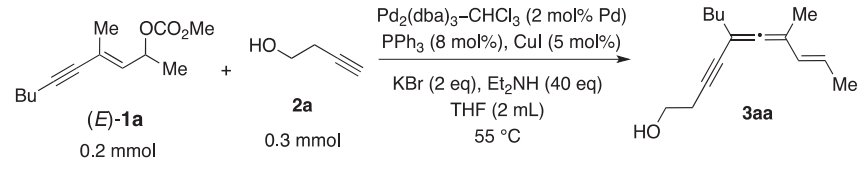

\begin{tabular}{|c|c|c|c|c|}
\hline Entry & Deviation from standard conditions & Time $(\mathrm{h})$ & Conv. (\%) & Yield $(\%)^{\mathrm{a}}$ \\
\hline 1 & none & 2.5 & 95 & $91^{\mathrm{b}}$ \\
\hline 2 & $\mathrm{Et}_{2} \mathrm{NH}$ (20 equiv) & 3 & 90 & 86 \\
\hline 3 & $\mathrm{Bu}_{2} \mathrm{NH}$ (20 equiv) & 3 & 83 & 79 \\
\hline 4 & $(i-\mathrm{Pr})_{2} \mathrm{NH}(20$ equiv $)$ & 3 & 75 & 74 \\
\hline 5 & $\mathrm{Et}_{3} \mathrm{~N}(20$ equiv $)$ & 3 & 60 & 57 \\
\hline 6 & no $\mathrm{KBr}$ & 3.5 & 75 & 72 \\
\hline 7 & $\mathrm{KI}$ (2 equiv), $\mathrm{Et}_{2} \mathrm{NH}$ (20 equiv) & 24 & 9 & 7 \\
\hline 8 & $\mathrm{LiBr}$ (2 equiv), $\mathrm{Et}_{2} \mathrm{NH}$ (20 equiv) & 16 & 56 & 48 \\
\hline 9 & $\mathrm{H}_{2} \mathrm{O}(100 \mu \mathrm{L}), \mathrm{Et}_{2} \mathrm{NH}$ (20 equiv) & 3 & 65 & 44 \\
\hline 10 & at $25^{\circ} \mathrm{C}, \mathrm{Et}_{2} \mathrm{NH}$ (20 equiv) & 8 & 52 & 44 \\
\hline
\end{tabular}

a Determined by ${ }^{1} \mathrm{H}$ NMR using $p$-anisaldehyde as the internal standard.

b Yield of isolated product is provided.

Having identified the set of optimised reaction conditions, we investigated the scope and limitation of various terminal alkynes for the method and the related results are listed in Table 2. Notably, the alkyl substituted alkynes were reagents well suited to the method (entries 1-4), despite the fact that the reaction of the relatively bulky alkyne 3,3-dimethylbut-1-yne (2d) with (E)-1a afforded the desired product 3ad in a moderate yield at a palladium loading of $2 \mathrm{~mol} \%$ (entry 3 ). Fortunately, a good level of 3ad yield could be achieved when the palladium content was increased to $4 \mathrm{~mol} \%$ (entry 4 ). It was also necessary to employ the method in the presence of at least $4 \mathrm{~mol} \%$ of Pd when using a silyl-substituted terminal alkyne in order to obtain the product 3ae, although only in a moderate yield (entry 5). Aryl acetylenes were observed to be less reactive compared to the alkyl acetylenes (entries 6-10). However, the phenylacetylene reactant containing an electron-donor group (2h) (entry 10) exhibited better performance than those having non-substituted or electron-poor phenyl rings (entries 6-9).

We next surveyed the suitability of the method for the coupling reaction of a number of enyne carbonates with diverse substitution patterns and the alkyne $\mathbf{2 a}$. The related results are listed in Table 3. The enyne $(E)-\mathbf{1 b}$ having a terminal alkynyl moiety $\left(\mathrm{R}^{1}=\mathrm{H}\right)$ was not a suitable substrate for the method, and led to a complex mixture (entry 1 ). Unexpectedly, a relatively low yield of the desired product 3ca was obtained from the enyne having a methyl-substituted alkynyl moiety (entry 2 ). Nevertheless, the yield of 3ca could be improved to moderate levels by using a tris(2-furyl)phosphine (TFP) ligand instead. The presence of bulky alkyl groups on the alkynyl moiety, such as Cy or $t$-Bu would not be a problem for the method; both reagents $\mathbf{1 d}$ and $\mathbf{1 e}$ reacted with $\mathbf{2 a}$ smoothly to provide high yields of the corresponding vinyl-allenynes (entries 3-5), albeit requiring a higher Pd loading. Only a moderate yield of 3fa yield could be isolated from the reaction of $\mathbf{1 f}$ where $\mathrm{R}^{1}$ is $\mathrm{Ph}$ and no benefit was gained from an increase in the palladium level or by the use of a TFP ligand (entries 6 and 7). On the contrary, running the reaction at the higher catalyst loading led to remarkably diminished recovery of the product, even though it provoked the conversion to somewhat higher level. This may be due to palladium-promoted decomposition of the relatively less stable products.

The $R^{2}$ group on the alkenyl carbon of $\mathbf{1}$ was also varied. The substrate $\mathbf{1 g}$ with a disubstituted alkenyl moiety reacted to give rise 3ga in high yield. However, 3ga was isolated with relatively lower purity probably because of its relatively low stability (entries 8 and 9). The substrate $\mathbf{1 h}$ having a $\mathrm{Bu}$ at $\mathrm{R}^{2}$ position reacted smoothly and yielded the allene product in high yield (entry 10), whereas the presence of a cyclohexyl or phenyl group at this position led to the recovery of the corresponding products in moderate yields only (entries 11-14).

The desired allene product 3ka from the reaction of primary enyne carbonate was also not so stable under the reaction conditions, which led to a lower yield by increasing the catalyst content

Table 2

The reaction of enyne carbonate 1a with various terminal alkynes.

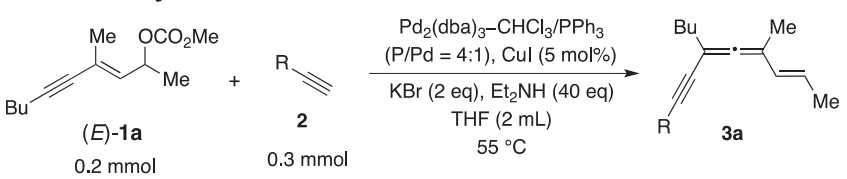

\begin{tabular}{|c|c|c|c|c|c|}
\hline Entry & $\mathrm{R}$ & $\mathrm{Pd}(\mathrm{mol} \%)$ & Time $(\mathrm{h})$ & Conversion (\%) & Yield (\%) \\
\hline 1 & Bu 2b & 2 & 1.5 & 92 & 88 3ab \\
\hline 2 & Су 2c & 2 & 2 & 86 & 82 3ac \\
\hline 3 & $t-B u 2 d$ & 2 & 2 & 66 & 64 3ad \\
\hline 4 & $t-\mathrm{Bu} 2 \mathbf{d}$ & 4 & 2.5 & 78 & 75 3ad \\
\hline 5 & $(i-\operatorname{Pr})_{3} \operatorname{Si} \mathbf{2 e}$ & 4 & 2 & 70 & 65 3ae \\
\hline 6 & $\mathrm{Ph} \mathbf{2 f}$ & 2 & 4 & 56 & 28 3af \\
\hline 7 & $\mathrm{Ph} \mathbf{2 f}$ & 4 & 1 & 77 & 69 3af \\
\hline 8 & $p-\mathrm{CF}_{3} \mathrm{C}_{6} \mathrm{H}_{4} \mathbf{2 g}$ & 2 & 2 & 35 & 28 3ag \\
\hline 9 & $p-\mathrm{CF}_{3} \mathrm{C}_{6} \mathrm{H}_{4} \mathbf{2 g}$ & 4 & 2 & 72 & 68 3ag \\
\hline 10 & $p-\mathrm{OMeC}_{6} \mathrm{H}_{4} \mathbf{2 h}$ & 2 & 2 & 85 & 74 3ah \\
\hline
\end{tabular}


Table 3

The reaction of enyne carbonates $(E)-\mathbf{1}$ with the alkyne $\mathbf{2 a}$.

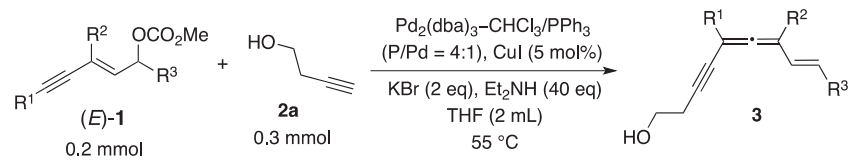

\begin{tabular}{|c|c|c|c|c|c|}
\hline Entry & $\mathrm{R}^{1}, \mathrm{R}^{2}, \mathrm{R}^{3}$ & $\operatorname{Pd}(\%)$ & Time (h) & Conv. (\%) & Yield (\%) \\
\hline 1 & H, Me, Me $\mathbf{1 b}$ & 2 & 1 & 100 & trace $\mathbf{3 b a}$ \\
\hline 2 & Me, Me, Me 1c & 4 & $1(4)^{a}$ & $40(64)^{a}$ & $35(61)^{a}$ 3ca \\
\hline 3 & Cy, Me, Me 1d & 2 & 3 & 77 & 71 3da \\
\hline 4 & Cy, Me, Me 1d & 4 & 5 & 92 & 85 3da \\
\hline 5 & $t$-Bu, Me, Me $\mathbf{1 e}$ & 4 & 1 & 96 & 90 3ea \\
\hline 6 & $\mathrm{Ph}, \mathrm{Me}, \mathrm{Me} \mathbf{1 f}$ & 2 & 1 & 78 & $61 \mathbf{3 f a}$ \\
\hline 7 & $\mathrm{Ph}, \mathrm{Me}, \mathrm{Me} \mathbf{1 f}$ & 4 & $1(1)^{a}$ & $85(36)^{a}$ & $42(25)^{\mathrm{a}} \mathbf{3 f a}$ \\
\hline 8 & $\mathrm{Bu}, \mathrm{H}, \mathrm{Me} \mathbf{1 g}$ & 2 & 0.5 & 86 & $68^{\mathrm{b}, \mathrm{c}} \mathbf{3 g a}$ \\
\hline 9 & $\mathrm{Bu}, \mathrm{H}, \mathrm{Me} \mathbf{1 g}$ & 4 & 1 & 95 & $86^{\mathrm{b}, \mathrm{d}} \mathbf{3 g a}$ \\
\hline 10 & $\mathrm{Bu}, \mathrm{Bu}, \mathrm{Me} \mathbf{1 h}$ & 2 & 2 & 85 & 84 3ha \\
\hline 11 & $\mathrm{Bu}, \mathrm{Cy}, \mathrm{Me} \mathbf{1 i}$ & 2 & 2 & 36 & $263 i a$ \\
\hline 12 & $\mathrm{Bu}, \mathrm{Cy}, \mathrm{Me} \mathbf{1 i}$ & 4 & 4 & 47 & $36 \mathbf{3 i a}$ \\
\hline 13 & $\mathrm{Bu}, \mathrm{Ph}, \mathrm{Me} \mathbf{1 j}$ & 2 & 1 & 78 & $44 \mathbf{3 j a}$ \\
\hline 14 & $\mathrm{Bu}, \mathrm{Ph}, \mathrm{Me} \mathbf{1 j}$ & 4 & 1.5 & 82 & $56 \mathbf{3 j a}$ \\
\hline 15 & $\mathrm{Bu}, \mathrm{Me}, \mathrm{H} \mathbf{1 k}$ & 2 & 1 & 67 & 47 3ka \\
\hline 16 & $\mathrm{Bu}, \mathrm{Me}, \mathrm{H} \mathbf{1 k}$ & 4 & 1 & 72 & 24 3ka \\
\hline 17 & $\mathrm{Bu}, \mathrm{Me}, \mathrm{Bu} \mathbf{1 1}$ & 2 & 2 & 66 & 65 3la \\
\hline 18 & Bu, Me, Bu 11 & 4 & 3 & 69 & 64 3la \\
\hline 19 & $\mathrm{Bu}, \mathrm{Me}, i$-Pr $\mathbf{1} \mathbf{m}$ & 2 & 1.5 & 52 & 35 3ma \\
\hline 20 & $\mathrm{Bu}, \mathrm{Me}, i-\operatorname{Pr} \mathbf{1} \mathbf{m}$ & 4 & 4 & 68 & 55 3ma \\
\hline 21 & $\mathrm{Bu}, \mathrm{Me}, \mathrm{Ph} \mathbf{1 n}$ & 2 & 0.5 & 100 & 90 3na \\
\hline
\end{tabular}

a Performed using tris(2-furyl)phosphine.

b Determined by ${ }^{1} \mathrm{H}$ NMR using $p$-anisaldehyde as the internal standard.

c Isolated with $88 \%$ purity.

d Isolated with $82 \%$ purity.

in the reaction medium (entries 15 and 16). It seems that the method is particularly sensitive to the size of allylic functionality of the secondary enyne carbonates. Lower yields were obtained as the size of this group became larger (entries 17-20). On the other hand it was a notable that the phenyl-substituted substrate 1n performed with very high reactivity, affording the desired 3na product in $90 \%$ yield with complete conversion within just $0.5 \mathrm{~h}$, probably owing to the favoured formation of the relatively stable phenyl-substituted $\pi$-allylpalladium intermediate (entry 21 ).

$(Z)$-Configured enyne carbonates are not such a suitable type of reagent for the method, probably due to their inherently more congested nature; the coupling of the enyne carbonate $(Z)-\mathbf{1 a}$ with $\mathbf{2 a}$ brought about the 3aa product in $44 \%$ yield only (Fig. 2).

Unfortunately, the method was not stereoselective in terms of axial chirality transfer from the centre. The reaction of an enantio-pure enyne carbonate $(R, E)-\mathbf{1 a}$ and $\mathbf{2 a}$ yielded the expected product only in racemic form (Fig. 3).

The method was also applied to enyne epoxide reagents. In contrast, however, to our previous studies where conjugated enyne oxiranes were found to be perfectly amenable reagents towards palladium-catalysed processes ${ }^{1 \mathrm{~d}, \mathrm{e}}$ yielded the expected allene product 5ab in relatively low yields (Fig. 4).

In accordance with our previous reports, the reaction should proceed through the formation of $\pi$-allylpalladium formation (A). Further migration of the organopalladium unit to the far alkynyl carbon (B) followed by reductive elimination should result in the product 3 (Fig. 5).

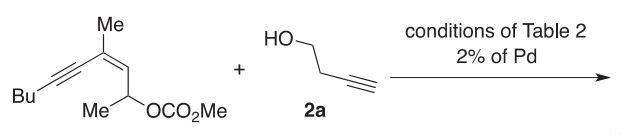

$(Z)-1 a$

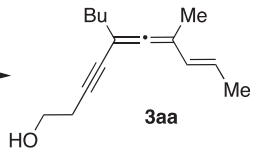

$44 \%$ yield
Fig. 2. Reaction of the (Z)-configured enyne carbonate 1a

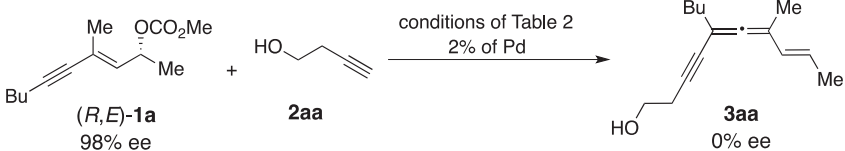

Fig. 3. Reaction of enantio-pure enyne carbonate.

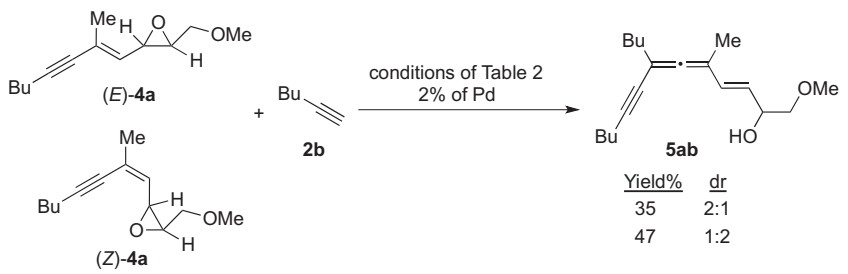

Fig. 4. Reaction of enyne 2-(methoxymethyl)-3-(2-methyloct-1-en-3-yn-1-yl)oxiranes with 1-hexyne.

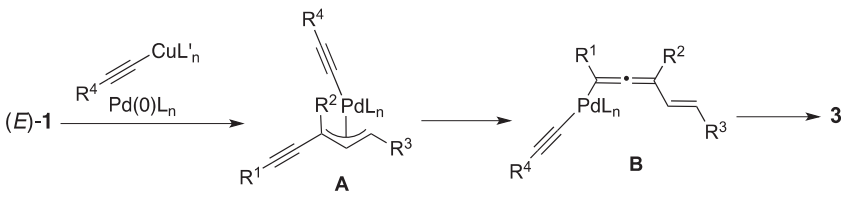

Fig. 5. Proposed mechanism.

Having established that the carbonates of 2-en-4yne alcohols are suitable reagents for alkynylation reactions with terminal alkynes, we have also evaluated the applicability of one of the vinylallenyne product of the study towards a $[4+2]$ cyclisation reaction. The reaction of 3ab with $\mathrm{N}$-phenylmaleimide proceeded with high 


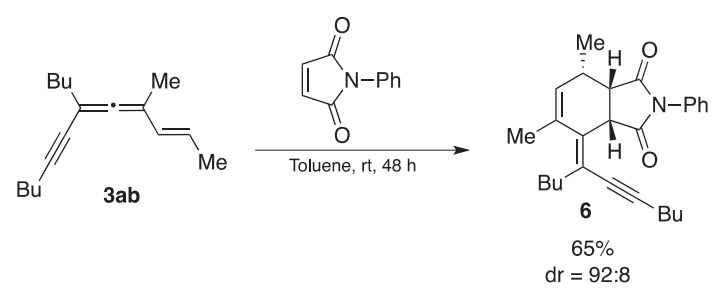

Fig. 6. $[4+2]$ Cyclization of 3ab and N-phenylmaleimide.

facial- and endo-selectivity to furnish a structurally interesting adduct with high diastereomeric ratio (dr) (Fig. 6).

In summary, the first palladium-catalysed alkynylation of 2-en4-yne carbonates has been established. The reactions proceeded effectively to yield vinyl-allenynes. One vinyl-allenyne product underwent [4+2] cyclisation with a dienophile with high facialand endo-selectivity.

\section{Acknowledgments}

The financial support of the Scientific and Technological Research Council of Turkey and Federal Ministry of Education and Research (Germany) via the Intensified Cooperation Program (201T092) and IZTECH 2013-iYTE-30 is gratefully acknowledged. We thank the Environmental Research Centre of Izmir Institute of Technology for HRMS and GC-MS analyses.

\section{A. Supplementary data}

Supplementary data associated with this article can be found, in the online version, at https://doi.org/10.1016/j.tetlet.2018.01.062.

\section{References}

1. (a) Palladium- and rhodium-mediated synthesis of vinylallenes: Akpınar GE, KuŞ M, Üçüncü M, Karakuș E, Artok L. Org Lett. 2011;13:748-751:

(b) Üçüncü M, Karakuş E, Kuş M, et al. J Org Chem. 2011;76:5959-5971;

(c) Karagöz EŞ, Kuş M, Akpınar GE, Artok L. J Org Chem. 2014;79:9222-9230;

(d) Kuş M, Artok L, Aygün M. J Org Chem. 2015;80:5494-5506;

(e) Ziyanak F, Artok L. 2017, submitted;

(f). Iron-mediated synthesis of vinylallenes: Taç D, Aytaç İA, Karatavuk AO, et al. Asian J Org Chem. 2017;6:1415-1420.

2. (a) A review including the applications of vinylallenes: Ma S. Chem Rev. 2005;105:2829-2871;

(b) Bertrand M, Grimaldi J, Waegel B. Chem Commun (London). 1968;1141-1142;

(c) Baudouy R, Delbecq F, Gore J. Tetrahedron. 1980;36:189-195;

(d) Schneider R, Siegel H, Hopf H. Liebigs Ann Chem. 1981;1812-1825;

(e) Hopf H. In Modern Allene Chemistry, Krause N, Hashmi ASK, Eds. Wiley-VCH,
Weinheim, 2004; Vol 1; pp 185-242.;

(f) Deutsch EA, Snider BB. J Org Chem. 1982;47:2682-2684;

(g) Tolstikov GA, Romanova TY, Kuchin AV. J Organomet Chem. 1985;285:71-82;

(h) Reich HJ, Eisenhart EK, Whipple WL, Kelly MJ. J Am Chem Soc 1988;110:6432-6442;

(i) Wang KK, Andemichael YW, Dhumrongvaraporn S. Tetrahedron Lett 1989;30:1311-1314;

(j) Wu KM, Midland MM, Okamura WH. J Org Chem. 1990;55:4381-4392;

(k) Koop U, Handke G, Krause N. Liebigs Ann. 1996;1487-1499;

(1) López S, Rodríguez J, Rey JG, de Lera AR. J Am Chem Soc. 1996;118:1881-1891;

(m) Murakami M, Itami K, Ito Y. J Am Chem Soc. 1997;119:7163-7164;

(n) Murakami M, Ubukata M, Itami K, Ito Y. Angew Chem Int Ed. 1998;37:2248-2250;

(o) Spino C, Thibault C, Gingras S. J Org Chem. 1998;63:5283-5287;

(p) Murakami M, Itami K, Ito Y. Organometallics. 1999;18:1326-1336;

(q) Murakami M, Itami K, Ito Y. J Am Chem Soc. 1999;121:4130-4135;

(r) Regás D, Afonso MM, Rodríguez ML, Palenzuela JA. J Org Chem. 2003;68:7845-7852;

(s) Murakami M, Ashida S, Matsuda TJ. J Am Chem Soc. 2004;126:10838-10839;

(t) Lee JH, Toste FD. Angew Chem Int Ed. 2007;46:912-914;

(u) Funami H, Kusama H, Iwasawa N. Angew Chem Int Ed. 2007;46:909-911;

(v) Souto JA, Pérez M, López CS, Alvarez R, Torrado A, de Lera AR. J Org Chem. 2010;75:4453-4462;

(w) Yang M, Yokokawa N, Ohmiya H, Sawamura M. Org Lett. 2012;14:816-819.

3. (a) Krause N. Liebigs Ann Chem. 1993;521-525;

(b) Schreiber SL, Kiessling LL. I Am Chem Soc. 1988;110:631-633;

(c) Gibbs RA, Bartels K, Lee RWK, Okamura WH. J Am Chem Soc. 1989;111:3717-3725.

4. (a) Elsevier CJ, Kleijn H, Ruitenberg K, Vermeer P. J Chem Soc, Chem Commun. 1983;1529-1530;

(b) Elsevier CJ, Kleijn H, Boersma J, Vermeer P. Organometallics. 1986;5:716-720;

(c) Wouters JMA, Klein RA, Elsevier CJ. Organometallics. 1994;13:4586-4593;

(d) Tsutsumi K, Ogoshi S, Kakiuchi K, Nishiguchi S, Kurosawa H. Inorg Chim Acta. 1999;296:37-44.

5. (a) Jeffery-Luong T, Linstrumelle G. Synthesis. 1983;32-34;

(b) Mandai $\mathrm{T}$, Nakata $\mathrm{T}$, Murayama $\mathrm{H}$, et al. Tetrahedron Lett. 1990;31:7179-7180;

(c) Mandai $\mathrm{T}$, Murayama $\mathrm{H}$, Nakata $\mathrm{T}$, et al. $J$ Organomet Chem. 1991;417:305-311;

(d) Gueugnot S, Linstrumelle G. Tetrahedron Lett. 1993;34:3853-3856;

(e) Darcel C, Bruneau C, Dixneuf PH. J Chem Soc, Chem Commun. 1994;1845-1846;

(f) Dixneuf PH, Dixneuf PH, Guyot T, Ness MD, Roberts SM. Chem Commun 1997:2083-2084;

(g) Condon-Gueugnot S, Linstrumelle G. Tetrahedron. 2000;56:1851-1857;

(h) Yoshida M, Hayashi M, Shishido K. Org Lett. 2007;9:1643-1646;

(i) Smith MK, Tunge JA. Org Lett. 2017;19:5497-5500.

6. (a) Celmer WD, Solomons IA. J Am Chem Soc. 1952;74:1870-1871;

(b) Celmer WD, Solomons IA. J Am Chem Soc. 1952;74:2245-2248;

(c) Celmer WD, Solomons IA. I Am Chem Soc. 1953;75:1372-1376;

(d) Bu'Lock JD, Jones ERH, Leeming PR. J Chem Soc. 1955;4270-4276;

(e) Anke T, Kupka J, Schramm G, Steglich WJ. Antibiotics. 1980;33:463-467;

(i) Ondeyka JG, Zink DL, Young K, et al. J Nat Prod. 2006;69:377-380;

(i) . For reviews on allenic natural products, see: Bew RE, Chapman JR, Jones ER, Lowe HBE, Lowe G. J Chem Soc C. 1966;129-135;

(k) Hoffmann-Röder A, Krause N. Angew Chem Int Ed. 2004;43:1196-1216;

(l) Hoffmann-Röder A, Krause N, In Modern Allene Chemistry; Krause N, Hashmi

AS K, Eds. Wiley-VCH, Weinheim, 2004; Vol. 1; pp 51-92.;

(m) Yua S, Ma S. Chem Comm. 2011;47:5384-5418 